\title{
Esophageal Malignant Peripheral Nerve Sheath Tumor
}

National Cancer Institute

\section{Source}

National Cancer Institute. Esophageal Malignant Peripheral Nerve Sheath Tumor. NCI

Thesaurus. Code C92185.

A malignant peripheral nerve sheath tumor that affects the esophageal wall. 